\title{
EDITORIAL
}

\section{LA ACREDITACIÓN EN LA U.D.C.A, UN CAMINO HACIA LA EXCELENCIA}

\author{
Germán Anzola Montero \\ Rector
}

La Rectoría de la U.D.C.A, con el decidido acompañamiento de la Asamblea de Fundadores y del Consejo Directivo, asumió como política institucional la consecución de certificaciones de alta calidad, incluyendo la ACREDITACIÓN, en sus diferentes modalidades de aplicación: la acreditación de los programas académicos y la acreditación a nivel institucional.

En este mismo sentido, abordamos la certificación ISO9001, en algunos procesos del área administrativa y financiera.

Trabajar para alcanzar estos reconocimientos, tanto por parte de la comunidad académica, como de la sociedad colombiana y del Estado, es la respuesta que hemos asumido con la responsabilidad social universitaria que nos caracteriza y que se adquirió hace 30 años, cuando el gobierno colombiano, por intermedio del Ministerio de Educación Nacional, le otorgó a la Institución la correspondiente Personería Jurídica.

Puede surgir la pregunta del porqué de esta determinación y nuestra respuesta se fundamenta en la concepción que la Universidad ha adoptado, desde su creación, de constituirse como un bien social del país, que presta un servicio público de carácter cultural y sin ánimo de lucro, para brindar educación superior de excelencia, para contribuir a la construcción de una sociedad con mayor bienestar, más justa, solidaria, equitativa, en paz y competitiva; y por supuesto, comprometida con la rendición de cuentas, como deber incondicional, en la prestación de este servicio público cultural. Es así, como la U.D.C.A a través del cumplimiento de sus funciones sustantivas: la docencia, la investigación y la proyección a la comunidad, garantiza a la sociedad, que cumple con las más altas condiciones de calidad, con los objetivos y con los propósitos que hemos declarado asumir.

Es, desde la perspectiva anterior, que hemos hecho nuestra consideración de la Universidad como formación "en lo superior para lo superior", asumiendo las palabras de mi gran Maestro el S.J. Alfonso Borrero Cabal; y, es desde aquí, donde la U.D.C.A decide aportarle al país, cumpliendo sus responsabilidades como una Universidad de excelencia, objetivo que asumimos el 29 de diciembre de 2004, cuan- do el Gobierno colombiano, por conducto del Ministerio de Educación Nacional, nos reconoció como UNIVERSIDAD, trabajando siempre con ahínco y con compromiso, lo que hoy se expresa en una docencia de la más alta calidad, una investigación con rigor científico y con resultados valorados y reconocidos por las comunidades de la ciencia nacional e internacional, y con vínculos cada vez más estrechos con la sociedad, mediante los cuales reintegramos a ella, los beneficios y servicios que nos demanda desde nuestra condición de Universidad dedicada al cultivo del saber, al enriquecimiento de la cultura y a la formación de hombres y mujeres éticos, idóneos y competentes.

Comprometernos con procesos y con modelos de autoevaluación con miras a la acreditación y como consecuencia de ello, asumir nuevos y rigurosos compromisos de autorregulación, es la única forma de demostrar, permanentemente, la calidad y la excelencia en nuestro diario quehacer. Este es nuestro deber como Universidad y por ello estamos actualmente avanzando en la re-significación de nuestro Proyecto Educativo Institucional -PEI- de modo que las orientaciones y políticas que allí se plasmen en lo académico y administrativo, no solo se coloquen en sintonía con los tiempos actuales (a nivel mundial y nacional), sino que sirvan de guía para la acción de los distintos actores institucionales comprometidos con el mejoramiento cualitativo y cuantitativo a nivel institucional, de programas, de cursos, de funciones y procesos, y como faro en la formulación de nuestros planes de desarrollo.

Íntimamente ligada a las condiciones de Calidad está la PERTINENCIA, entendiendo por ella el cumplimento o adecuación de lo que la Universidad hace con respecto a lo que la sociedad le demanda, es decir a trabajar con el conocimiento, a su transmisión, producción, transferencia y aplicación y, a colocar ese conocimiento al servicio de la sociedad. Aquí es donde la Universidad demuestra su responsabilidad y compromiso con la sociedad, incluyendo la actuación profesional de los egresados. Ser de excelencia es formar en los niveles de pregrado y de postgrado, para el ejercicio profesional responsable, lo que significa estar al servicio de la 
sociedad, es decir, aportando soluciones a los problemas del mundo moderno, tales como seguridad alimentaria, cambio climático, la salud, la igualdad, la justicia social, el cumplimiento de los derechos humanos, la interculturalidad la paz, las relaciones con el ambiente, las formas de vida, la ética, los valores individuales y generales y el afianzamiento de verdaderos e igualitarios sistemas democráticos. Esto es lo que en la U.D.C.A debemos considerar como formación pertinente y transformadora, conducente a una mayor equidad social y a la creación de una conciencia crítica de la sociedad.

Cumplir con los objetivos que nos hemos propuesto, debe conducir a una mayor credibilidad y calidad en todos los procesos propios de una Universidad y, por ello, esperamos fortalecer nuestra presencia en redes académicas y científicas, del orden nacional e internacional, pues somos conscientes que es sobre procesos de cooperación, de intercambio y de la creación de sinergias, como podemos fortalecernos como Universidad y desde donde podemos aportar con nuestras experiencias y saberes.

Finalmente, quiero concluir con una serie de enunciados, que nos lleven a la reflexión y que permitan afianzar el proceso que adelantamos de autoevaluación con miras a la acreditación institucional, demostrando:

- Que le cumplimos a la sociedad colombiana.

- Que formamos profesionales que sí aportan a la solución de las necesidades y de los problemas del país.
- Que tenemos la plena convicción de estar alcanzando, cada vez mejores desempeños y logros que ameritan el reconocimiento externo (de la comunidad académica, de la sociedad y del Estado) y la respectiva valoración de nuestro quehacer institucional, reafirmando nuestra realidad, identidad y paradigma, propios de la U.D.C.A.

- Que prestamos un servicio universitario de excelencia.

- Que somos una organización social con enfoques y con fines propios, trabajando en lo "superior y para lo superior", y que todo lo anterior es lo que nos conducirá a la Acreditación Institucional, toda vez que podemos evidenciar idoneidad, pertinencia, responsabilidad, integridad, equidad, coherencia, universalidad, transparencia, eficacia y eficiencia.

Concluyo: Como universidad joven, en crecimiento y en permanente desarrollo, la U.D.C.A, haciendo uso responsable de su autonomía, ha venido aplicando procesos de autoevaluación y de autorregulación que han derivado en importantes acciones de mejoramiento, comprometiéndonos así con la excelencia que nos ha de conducir a la Acreditación Institucional y a un mayor reconocimiento académico y social. Es indiscutible el gran trabajo que nos espera; por ello quiero invitar a toda la comunidad universitaria a dedicar todos nuestros esfuerzos, para alcanzar este merecido reconocimiento. 